\section{The long and short of fat}

\section{By Lev Osherovich, Senior Writer}

With patent protection for Roche's Xenical orlistat set to expire in 2009, the obesity drug's $\$ 531$ million in 2007 sales will soon be up for grabs. Now, two mouse studies make a case for blocking receptors for free fatty acids-short chain in one case and long chain in the other-that are downstream of Xenical's target. Although some drug developers already have explored brain- and pancreas-specific homologs of one of these receptors to treat metabolic diseases, hitting the intestinal version could bypass some of Xenical's side effects while still blocking fat absorption.

Xenical works by blocking pancreatic lipase, an enzyme secreted into the intestine that liberates dietary fatty acids from a triglyceride precursor form, causing triglycerides to pass through the digestive tract.

The new studies show that fatty acids can also engage surface receptors that influence fatty acid transport, metabolism and appetite.

One study focused on modulating free fatty acid receptor 3 (FFAR3; GPR41), a receptor for short-chain fatty acids like acetate and propionate that are produced by intestinal microbes. ${ }^{1}$ The second study described how a receptor called CD36 molecule (thrombospondin receptor) (SCARB3; FAT; CD36) senses oleate, a long-chain fatty acid, thus stimulating a pathway leading to satiety. ${ }^{2}$

\section{Short and sweet}

The GPR41 study was published in Proceedings of the National Academy of Sciences by a team led by Masashi Yanagisawa, professor of molecular genetics at the University of Texas Southwestern Medical Center, and Jeffrey Gordon, director of the Center for Genome Sciences at the Washington University School of Medicine.

The work builds on earlier efforts to characterize the location and function of GPR41 and its close relatives, GPR40 and GPR43. Because the ligands for this receptor family were recognized as dietary fatty acids, the proteins became interesting obesity targets for at least two companies.

Modulating GPR40 and GPR43 activity already has been attempted by GlaxoSmithKline plc and Amgen Inc., according to published studies., ${ }^{3,4}$ A GSK spokesperson told SciBX the company's project in this area is no longer active for undisclosed reasons. Amgen's GPR43 program also is no longer active, according to a company spokesperson.

But whereas GPR40 and GPR43 are found in multiple tissues, including the brain and pancreas, Yanagisawa and Gordon's team discovered that GPR41 was expressed primarily in the enteroendocrine cells of the intestinal ileum and colon.

Thus, as an intestinal surface protein, GPR41 may in fact be more druggable than its counterparts in the brain and pancreas.

"Apparently, animals use this receptor to monitor what's going on in the intestinal lumen," Yanagisawa told SciBX.

Short-chain free fatty acids constitute about $10 \%$ of dietary energy and arise through fermentation of dietary fiber by intestinal bacteria. The team found that GPR41 knockouts, which cannot detect short-chain fatty acids, had less adiposity and body weight than wild-type controls.

"In the absence of this receptor, the animal is unable to extract the full amount of energy from food," said Yanagisawa.

To prove that GPR41 knockouts miss out on extra calories made available by intestinal bacteria, the team eliminated the bacteria in both types of mice and found that GPR41 knockout mice now weighed the same as similarly treated wild-type controls.

"The difference in body weight caused by deletion of GPR41 disappears when there are no intestinal bacteria," said Yanagisawa.

Yanagisawa suspects that GPR41 senses short-chain fatty acids and triggers their uptake into the cell by an as yet unknown transport mechanism. He noted that GPR41 knockouts had normal food intake but poorer caloric extraction than wild-type mice.

Indeed, the feces of GPR41 knockout mice had higher short-chain fatty acid levels than did feces of wild-type controls. This suggests that without GPR41, the energy-bearing molecules slip right through the digestive tract without being absorbed.

"This paper is significant in that it provides a mechanistic understanding of the regulation of host metabolism by gut microbes and provides a therapeutic target" for obesity, said Geetha Rayasam, a senior scientist at Ranbaxy Laboratories Ltd. who recently published a review of the fatty acid receptor field. ${ }^{5}$

Blocking the absorption of short-chain fatty acids also may be a better therapeutic strategy than using a broad-spectrum fat blocker like Xenical. Yanagisawa noted that GPR41 knockouts were otherwise healthy and did not have steatorrhea, the fatty diarrhea that is an unpleasant side effect of Xenical.

His next step is to develop selective GPR41 antagonists and to test the effect of GPR41 inhibition in a mouse model of obesity.

Yanagisawa and Gordon have not sought patents for the discoveries reported in the PNAS paper.

\section{The long of it}

Meanwhile, a paper in Cell Metabolism shows that long-chain fatty acids act in the intestine to trigger a fat-sensing cue to stop eating. The study, from the laboratory of Daniele Piomelli, professor of pharmacology at the University of California, Irvine, points to the fat receptor CD36 as one of several possible therapeutic targets to improve fat-induced satiety.

Piomelli's team previously identified a fatty acid metabolite called oleoylethanolamide (OEA) as an intracellular signal for satiety in the 


\section{TARGETS \& MECHANISMS}

intestine. ${ }^{6}$ In mice, OEA levels rise after feeding and block the desire to eat again, thus delaying the next meal.

In the new study, Piomelli's group set out to find the origin of OEA by infusing various nutrients into the upper intestine of mice and measuring OEA production.

"We found that only fat, not sugar or protein, stimulates the production of OEA," said Piomelli. "We also found that only unsaturated fats like oleic acid specifically had this effect."

Oleate is one of several possible chemical precursors to OEA. As a result, Piomelli hypothesized that the long-chain fatty acid is transported into the cell and enzymatically converted to OEA.

Indeed, CD36 knockout mice, which do not readily take up oleate, showed less induction of OEA after feeding than wild-type mice. The knockouts did not lower their food intake when their intestines were perfused with a lipid-rich cocktail, unlike wild-type controls.

Although modulating OEA production or degradation seems like a promising approach, Piomelli cautioned that the enzymes involved in OEA metabolism are also part of the endocannabinoid signaling mechanism, which has been targeted for obesity but has caused psychiatric side effects.?

On the other hand, Piomelli's team found that the downstream effector of OEA is peroxisome proliferator-activated receptor- $\alpha$ (PPAR- $\alpha$ ), the target of several drugs including Tricor fenofibrate, which is marketed to treat dyslipidemia by Solvay S.A. and Abbott Laboratories.

Piomelli thinks the broad effects of PPAR- $\alpha$ agonists on gene expression and lipid metabolism may be undesirable when treating obesity alone. Thus, activating CD36 could be a relatively low-risk alternative to directly targeting PPAR- $\alpha$ or cannabinoid signaling.

"It would be interesting to have a short-lived agonist of CD36 to stimulate the OEA pathway," he said.

Although most oleate imported by CD36 is repackaged into triglycerides, a small fraction is converted into OEA, which negatively regulates subsequent fatty acid ingestion. Thus, CD36 acts as a sort of gatekeeper to several branches of lipid metabolism.

Indeed, Scott Turner, VP of R\&D at KineMed Inc., said Piomelli's study focuses on a branch of the lipid uptake pathway that has been overlooked by companies.

A close homolog of CD36 called scavenger receptor class B member 1 (SCARB1) plays a role in hepatic cholesterol uptake and is the subject of a preclinical program at KineMed targeting reverse cholesterol transport to treat atherosclerosis.

"CD36 is a category of membrane transporters that perform many different functions" including free fatty acid uptake, cholesterol uptake and even reverse cholesterol transport, said Turner.

In light of Piomelli's findings, he said it may be useful to "look at how CD36 and OEA affect triacylglyceride assembly rates."
Piomelli has not sought patents for the work reported in the Cell Metabolism article. However, modulating OEA levels to treat obesity falls under earlier patents held by the University of California. He told SciBX those patents are available for licensing.

\section{Common ground}

It's also possible that the pathways for sensing short- and long-chain fatty acids have common downstream effectors. The PNAS study suggests that short-chain fatty acids are actively imported into the cells by a transporter that is regulated by GPR41 activity. Yanagisawa said it is unclear whether this is done by CD36 or an unrelated class of transporters.

However, he noted that the chemical differences between short- and long-chain fatty acids may mean that distinct mechanisms are involved in the transport of each type of molecule.

To get at these questions, Piomelli plans to further characterize the feeding behavior of CD36 knockouts. Likewise, Yanagisawa plans to test the effect of OEA on GPR41 activity.

Osherovich, L. SciBX 1(40); doi:10.1038/scibx.2008.964

Published online Nov. 6, 2008

\section{REFERENCES}

1. Samuel, B.S. et al. Proc. Natl. Acad. Sci. USA; published online Oct. 17, 2008;

doi:10.1073/pnas.0808567105

Contact: Jeffrey I. Gordon, Washington University School of Medicine, St. Louis, Mo.

e-mail: jgordon@wustl.edu

Contact: Masashi Yanagisawa, University of Texas Southwestern

Medical Center, Dallas, Texas

e-mail: masashi.yanagisawa@utsouthwestern.edu

2. Schwartz, G.J. et al. Cell Metab.; published Oct. 7, 2008;

doi:10.1016/j.cmet.2008.08.005

Contact: Daniele Piomelli, University of California, Irvine, Calif. e-mail: piomelli@uci.edu

3. Covington, D.K. et al. Biochem. Soc. Trans. 34, 770-773 (2006)

4. Lee, T. et al. Mol. Pharmacol.; published online Sept. 25, 2008; doi:10.1124/mol.108.049536

5. Rayasam, G.V. et al. Expert Opin. Ther. Targets 11, 661-671 (2007)

6. Fu, J. et al. Nature 425, 90-93 (2003)

7. Fulmer, T. BioCentury 16(47), A9-A10; Oct. 20, 2008

\section{COMPANIES AND INSTITUTIONS MENTIONED}

Abbott Laboratories (NYSE:ABT), Abbott Park, III. Amgen Inc. (NASDAQ:AMGN), Thousand Oaks, Calif. GlaxoSmithKline plc (LSE:GSK; NYSE:GSK), London, U.K. KineMed Inc., Emeryville, Calif.

Ranbaxy Laboratories Ltd. (NSE:RANBAXY; BSE:500359),

Gurgaon, India

Roche (SWX:ROG), Basel, Switzerland

Solvay S.A. (Euronext:SOLB), Brussels, Belgium

University of California, Irvine, Calif.

University of Texas Southwestern Medical Center, Dallas, Texas Washington University School of Medicine, St. Louis, Mo. 